\title{
EVALUATION OF PERFORMANCE OF MATURED HYDRAULIC GROUTS: STRENGTH DEVELOPMENT, MICROSTRUCTURAL CHARACTERISTICS AND DURABILITY ISSUES
}

\author{
ANDRONIKI MILTIADOU-FEZANS ${ }^{1 *}$, MICHAIL DELAGRAMMATIKAS ${ }^{2}$, ANNA $^{*}$ \\ KALAGRI AND PANAYOTA VASSILIOU ${ }^{2}$
}

\author{
${ }^{1}$ School of Architecture \\ National Technical University of Athens (NTUA) \\ Patission42, 10682 Athens, Greece \\ e-mail: amiltiad@central.ntua.gr(*corresponding author) \\ ${ }^{2}$ School of Chemical Engineering \\ National Technical University of Athens (NTUA) \\ Zografou Campus, IroonPolytechneiou9, 15780 Athens, Greece \\ email:mdel@mail.ntua.gr,pvas@chemeng.ntua.gr
}

Keywords: Grout, natural hydraulic lime (NHL), pozzolan, performance, mature specimens, durability

\begin{abstract}
The present paper evaluates the performance of matured hydraulic grouts, with respect to their composition and the induced microstructural characteristics. Four different grout compositions were examined; three grouts based on natural hydraulic lime (NHL5), plain and in combination with pozzolan, and a ternary white cement - pozzolan - hydrated lime mixture. Both grout-only specimens and composite injected material have been examined and injected grout - masonry material interaction issues are discussed.
\end{abstract}

\section{INTRODUCTION}

Grouting constitutes one of the most common techniques applied for the repair and strengthening of historic masonry structures or fissured architectural members, when interconnected voids are present. Systematic research has been undertaken for the performance evaluation of various types of grouts and specific design criteria have been developed [1-9]. This technique is also used for the in-situ conservation of detached or cracked mosaics, wall paintings or frescoes and other valuable decorative surfaces [10-13]. Given the fact that it is a non-reversible intervention, a holistic methodology has to be adopted both for the design of the grout and the method of its application [14].

A series of research works for the performance evaluation of natural hydraulic lime (NHL) grouts, realized during the last decades, have proved the mechanical efficiency of this type of grouts for the structural restoration of stone masonry [3, 4, 6, 15-23]. Due to the similarity with the in-situ materials, natural hydraulic lime grouts are favoured in structural restoration of historic masonries, constituting a reliable alternative to higher strength ternary cementitious grouts (with low cement content). Thus, further systematic research for the optimization of NHL-based grouts, with respect to their composition and taking into account both fresh and hardened state properties over time, is of great interest. 
The aim of this work is to investigate the performance of three NHL grout compositions along with a ternary mixture, by studying their physicochemical, mechanical and durability characteristics. Fresh state injectability, as well as hardened state mechanical properties at 28, 90 and 365 days are presented first. Subsequently, physicochemical, mechanical, microstructural characteristics and durability to soluble salts of matured specimens of these grouts are studied and commented upon. The paper is concluded with the presentation of the results of representative samples selected from injected mosaic substrata (constructed on wall models, damaged and then consolidated with grouts) and examined by SEM/EDS and XRD, providing data on their penetration capacity and their solidification inside porous media.

\section{MATERIALS AND METHODS}

\subsection{Grouts composition, mixing procedure and fresh state properties}

Three different grouts based on natural hydraulic lime NHL5, plain or mixed with pozzolan of type I and a ternary grout, of low alkali and sulphate content white cement, mixed with hydrated lime powder and pozzolan of type II, were examined (Table 1). Both pozzolans are natural, finely ground materials with pozzolanicity of $7.5 \mathrm{~N} / \mathrm{mm}^{2}$ and $5.8 \mathrm{~N} / \mathrm{mm}^{2}$ respectively.

Table 1: Composition of the grouts

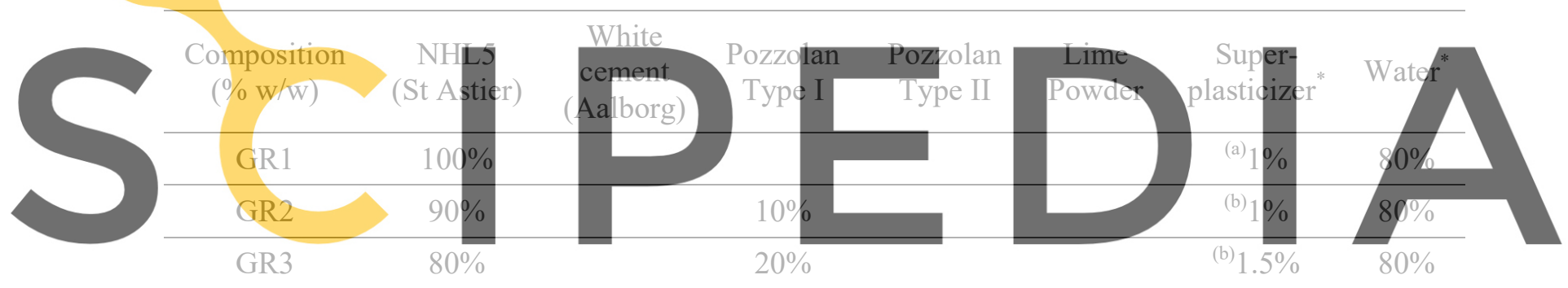

Register for freestat https//www.scipedia.com to downl@atd the version withiout the \&hatermark

Notes: Superplasticizers are based on (a) modified lignonaphthalene salts (CHEM SPL TM, Domylco), (b) polyether carboxylates (CHEMIUM 172 ${ }^{\mathrm{TM}}$, Domylco) and (c) naphthalenesulfonate polymer (RHEOBUILD TM 5000, Basf); * superplasticizer and water percentage refer to the grout solids total mass.

The design of the grouts was performed with the aim to ensure high injectability under low pressure $(\sim 0.075 \mathrm{MPa})$, even in voids and cracks of nominal minimum width $\left(\mathrm{W}_{\text {nom }}\right)$ equal to $0.2 \mathrm{~mm}$. For this purpose, the penetrability, fluidity and stability characteristics of the suspensions were fully examined. Based on the design criteria proposed in literature $[7,8,9]$, a water to solids ratio equal to 0.80 was experimentally determined, together with the adequate type and dosage of superplasticizer. The standardized sand column test method (EN 1771) was applied to check the penetrability and fluidity, along with the determination of the Fluidity Factor (using a Marsh cone of $3 \mathrm{~mm}$ nozzle diameter) and the flow time of $500 \mathrm{ml}$ of grout, out of $1000 \mathrm{ml}$ inserted in a Marsh cone of $4.75 \mathrm{~mm}$ nozzle diameter (EN445); stability of the suspension was studied using NF P18-359 (Table 2). An ultrasound dispersion mixer of $28 \mathrm{kHz}$, assisted by simple mechanical stirring at $300 \mathrm{rpm}$, was employed for the laboratory preparation of the mixtures. The mixing time was 3-4 min for the NHL-based grouts and 6 min for the ternary grout ( $2 \mathrm{~min} /$ solid component). 


\subsection{Mechanical tests}

For the evaluation of the mechanical properties of the grouts, prismatic specimens $(40 \times 40 \times 160 \mathrm{~mm})$ were prepared and moulded in the laboratory. The curing conditions were kept constant at $90 \pm 5 \% \mathrm{RH}$ and $20{ }^{\circ} \mathrm{C}$ (EN 459/2) until the execution of the tests at the ages of 28, 90 days and 12 months, using a Tritech $100 \mathrm{kN}$ Wykeham Farrance machine at 0.05 $\mathrm{mm} / \mathrm{min}$ and $0.1 \mathrm{~mm} / \mathrm{min}$ loading rate in flexion and compression, respectively (Table 2). For the determination of the flexural strength, three prismatic specimens were tested under a three-point bending arrangement. After a period of about 2 years, during which the specimens were preserved in the environmental chamber, they were removed and kept at $90 \pm 5 \% \mathrm{RH}$ at room temperature up to the age of 14 years. The matured grout specimens were tested in compression using the same apparatus and loading conditions.

\subsection{Examination of microstructural characteristics of matured grouts}

Porosity and porous size distribution were examined by mercury intrusion porosimetry (MIP) at the age of 14 years using a Quantachrome Autoscan 60 Porosimeter composed of two units, for low (24 psi) and for high (60000 psi) pressure. For the evaluation of large void volumes, polished specimens were examined by SEM/EDS (FEI Quanta 200 coupled with an EDAX detector) at low magnifications and the micrographs were analysed by digital image processing (DIP) using ImageJ FIJI software [24], while the EDS elemental analysis results were used in order to evaluate the cementation index of each composition. Mineralogical analysis was performed X-ray diffraction (X)
ADVANCE apparatus, equipped with a Lynxe
The water absorption coefficient by capil
NORMAL $11 / 85$. A notable variation from th
grout specimens were dried at a temperature of
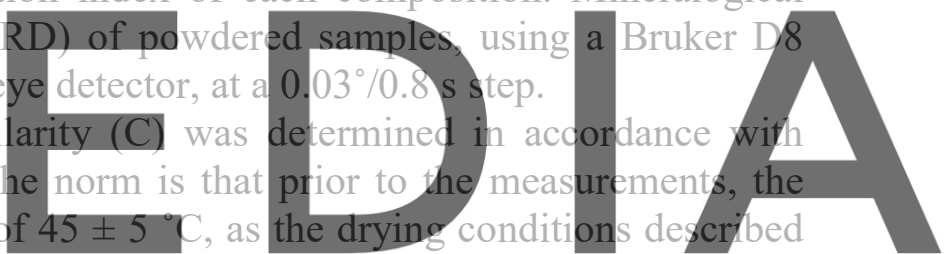

in the standard are too severe for grouts.

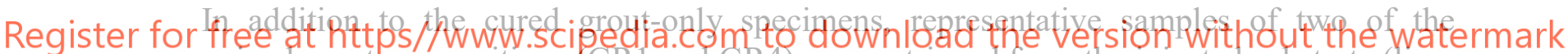
examined grout compositions (GRl and GR4) were retrieved from the injected substrata (lime and OPC based mortars respectively), bearing the mosaics attached on three-leaf wall models, constructed in the framework of a research project for grouting strengthening of three-leaf masonry $[4,6]$. These specimens, taken from the injected wallettes -matured indoors until the execution of the mechanical tests and then exposed to outdoors conditions, without any particular curing- were examined by SEM/EDS, XRD and MIP, in order to qualitatively evaluate their preservation state, the penetration capacity of the grout, its bonding with the wall inner materials and the mosaic substrata, as well as its microstructure, chemical and mineralogical composition.

\subsection{Durability of grouts to sodium sulphate salt crystallization test}

The salt crystallization damage is one of the most common causes of porous building materials deterioration. The mechanisms of crystallization, crystal growth and crystallisation pressure inside the pores of building materials [25], as well as their consequent degradation patterns (crack development, pulverisation, crumbling, flaking etc.) were extensively studied and analysed [26]. A number of factors influence this phenomenon, such as the building 
materials porosity, the porous size distribution and morphology, the composition of the salt solution, the wettability of the porous media, as well as environmental parameters.

In the present study sodium sulphate salt durability tests were carried out according to the

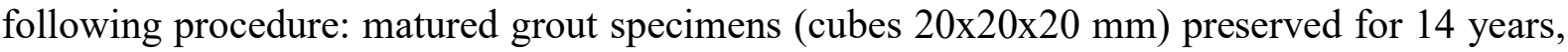
in the same conditions as presented in paragraph 2.2, were impregnated in $10 \% \mathrm{w} / \mathrm{w}$ sodium sulphate $\left(\mathrm{Na}_{2} \mathrm{SO}_{4}\right)$ solutions and dried for six cycles at $20^{\circ} \mathrm{C}$. After the sixth cycle, half of the specimens were dried at $20^{\circ} \mathrm{C}$ and the others at $50^{\circ} \mathrm{C}$ until constant mass was reached.

\section{RESULTS AND DISCUSSION}

\subsection{Rheological, physico-mechanical, chemical and microstructural characteristics}

As presented in Table 2, all the grout compositions met the following injectability criteria: the time required for the grout to reach the top of the sand column penetrability test $(\mathrm{h}=36$ $\mathrm{cm}$ ) was set to less than $50 \mathrm{~s}\left(\mathrm{~T}_{36} \leq 50 \mathrm{~s}\right)$; the Fluidity Factor values had to be higher than $0.7 \times 10^{3} \mathrm{~mm} / \mathrm{s}$ and the total efflux time of $500 \mathrm{ml}$ of grout out of $1000 \mathrm{ml}$ inserted in the cone (measured with a Marsh cone having a $4.75 \mathrm{~mm}$ nozzle diameter) had to be between $20 \mathrm{~s}$ and $45 \mathrm{~s}\left(20 \mathrm{~s} \leq \mathrm{t}_{\mathrm{d}=4.75} \leq 45 \mathrm{~s}\right)$; the maximum acceptable limit for the bleeding test was set to $5 \%$ $[1,7,8,9]$.

Table 2: Rheological, mechanical and hydric characteristics of the grouts

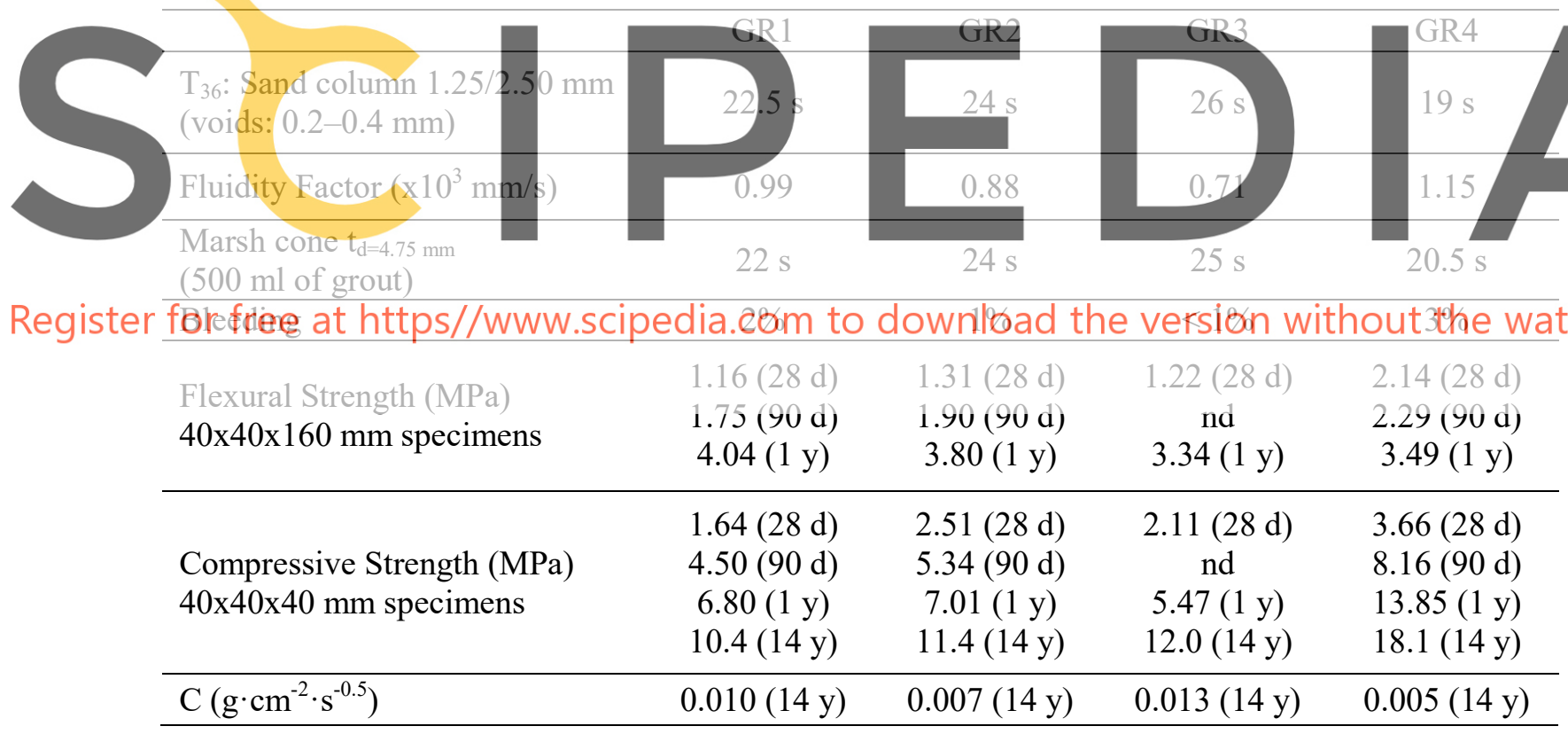

The mechanical properties of the NHL5-based grouts, especially compressive strength, are generally improved with the addition of pozzolan due to the stable products produced by the pozzolanic reaction, resulting to a pore refinement as indicated by MIP measurements (Table 3 ). Increasing the addition of pozzolan from $10 \%$ to $20 \%$ leads to a small decrease of the strength during the early ages, which is probably attributed to the slow rate of the pozzolanic reaction. These results highlight the need for a more systematic research regarding the various component dosage, with the aim to reach an optimization, when complete consumption of 
portlandite is sought. Given that the reactivity of a pozzolan is highly dependent on its composition and granulometry, a generalized model of the pozzolanic reactivity cannot exist. Thus, every new pozzolan in the NHL5-pozzolan system requires a different systematic study. Nevertheless, the mechanical properties of matured NHL5-based grouts, measured in the present study, proved to be very satisfactory, indicating that the addition of pozzolan has a significant positive effect to the strength development over time. Unfortunately, there were no matured specimens suitable to test in flexion, so these interesting findings can only be validated, as far compressive strength is concerned.

SEM backscattered electrons micrographs (Fig. 1) show that the grout microstructure at the age of 14 years appears denser in the case of ternary grout and hydraulic lime grouts with $20 \%$ pozzolan. The evident reduction of large void volumes with the addition of pozzolan was quantified by DIP (Fig. 2).
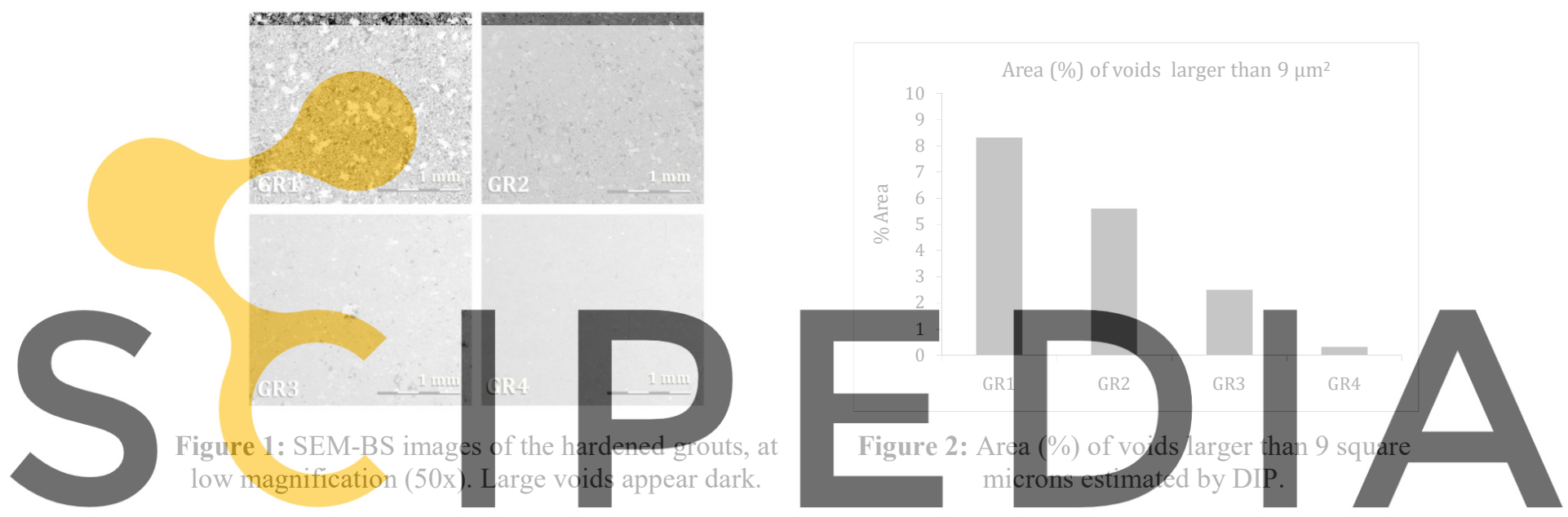

Table 3: Microstructural characteristics of the grouts cured up to 14 years based on MIP results

Register for free at https//WWW.scipedia.com to download the version without the watermark

\begin{tabular}{|c|c|c|c|c|c|}
\hline \multicolumn{2}{|c|}{ Total Porosity (\%) } & 52.2 & 47.2 & 51.4 & 49.6 \\
\hline \multicolumn{2}{|c|}{ Total intruded volume $\left(\mathrm{cm}^{3} / \mathrm{g}\right)$} & 0.556 & 0.459 & 0.481 & 0.458 \\
\hline \multicolumn{2}{|c|}{$\mathrm{d}_{\text {bulk }}\left(\mathrm{g} / \mathrm{cm}^{3}\right)$} & 0.938 & 1.029 & 1.068 & 1.084 \\
\hline \multicolumn{2}{|c|}{$\mathrm{d}_{\text {apparent }}\left(\mathrm{g} / \mathrm{cm}^{3}\right)$} & 1.931 & 1.929 & 2.168 & 2.129 \\
\hline \multirow{2}{*}{$\begin{array}{l}\text { Low } \\
\text { pressure }\end{array}$} & Fraction of pores $(5-110 \mu \mathrm{m})$ & $1.4 \%$ & $1.1 \%$ & $1.2 \%$ & $1.1 \%$ \\
\hline & Mean pore radius $(\mu \mathrm{m})$ & 29.93 & 11.7 & 11.07 & 12.6 \\
\hline \multirow{2}{*}{$\begin{array}{l}\text { High } \\
\text { pressure }\end{array}$} & Fraction of pores $(0.002-5 \mu \mathrm{m})$ & $98.6 \%$ & $98.9 \%$ & $98.8 \%$ & $98.9 \%$ \\
\hline & Mean pore radius $(\mu \mathrm{m})$ & 0.022 & 0.020 & 0.019 & 0.015 \\
\hline
\end{tabular}

Water absorption measurements show that the NHL5-based grouts exhibit higher water absorption rates (about twofold) compared to the ternary grout, which is mainly attributed to the presence of pores of large sizes. The addition of $10 \%$ pozzolan reduced the rate of absorption compared to the plain NHL5 grout and this is linked to the relative decrease in pore size due to the pozzolanic activity. The opposite is observed for the addition of $20 \%$ 
pozzolan which leads to higher absorption rate attributed probably to the pore size distribution and their interconnection.

The cementation index (C.I.) based on Boynton equation, was calculated, using the SEM/EDS analysis results, for all the grouts under study at the age of 14years in order to evaluate the hydraulicity of the mixtures. The data of Table 3 reveal that the addition of pozzolan increases the hydraulicity index of the NHL5 grouts. It is notable that the CI value of the grout GR3 and that of the ternary grout GR4 are very similar.

Table 3: Results of SEM-EDS analysis normalized and expressed as element oxides and the calculated cementation index (CI). Concentrations correspond to full frame analysis of the images presented in Figure 1.

\begin{tabular}{lcccc}
\hline Element oxide (\% wt) & GR1 & GR2 & GR3 & GR4 \\
\hline $\mathrm{Na}_{2} \mathrm{O}$ & 0.88 & 0.78 & 1.10 & 1.15 \\
$\mathrm{MgO}$ & 2.12 & 2.07 & 1.14 & 1.02 \\
$\mathrm{Al}_{2} \mathrm{O}_{3}$ & 2.85 & 4.21 & 4.90 & 6.15 \\
$\mathrm{SiO}_{2}$ & 25.77 & 30.28 & 39.17 & 41.53 \\
$\mathrm{SO}_{3}$ & 0.98 & 1.89 & 0.65 & 0.88 \\
$\mathrm{Cl}_{2} \mathrm{O}$ & 0.00 & 0.90 & 0.70 & 0.36 \\
$\mathrm{~K}_{2} \mathrm{O}$ & 0.51 & 0.50 & 2.06 & 1.65 \\
$\mathrm{CaO}$ & 65.72 & 58.10 & 49.18 & 45.82 \\
$\mathrm{Fe}_{2} \mathrm{O}_{3}$ & 1.20 & 1.27 & 1.11 & 1.42 \\
\hline C.I. & 1.11 & 1.48 & 2.28 & 2.63 \\
\hline
\end{tabular}
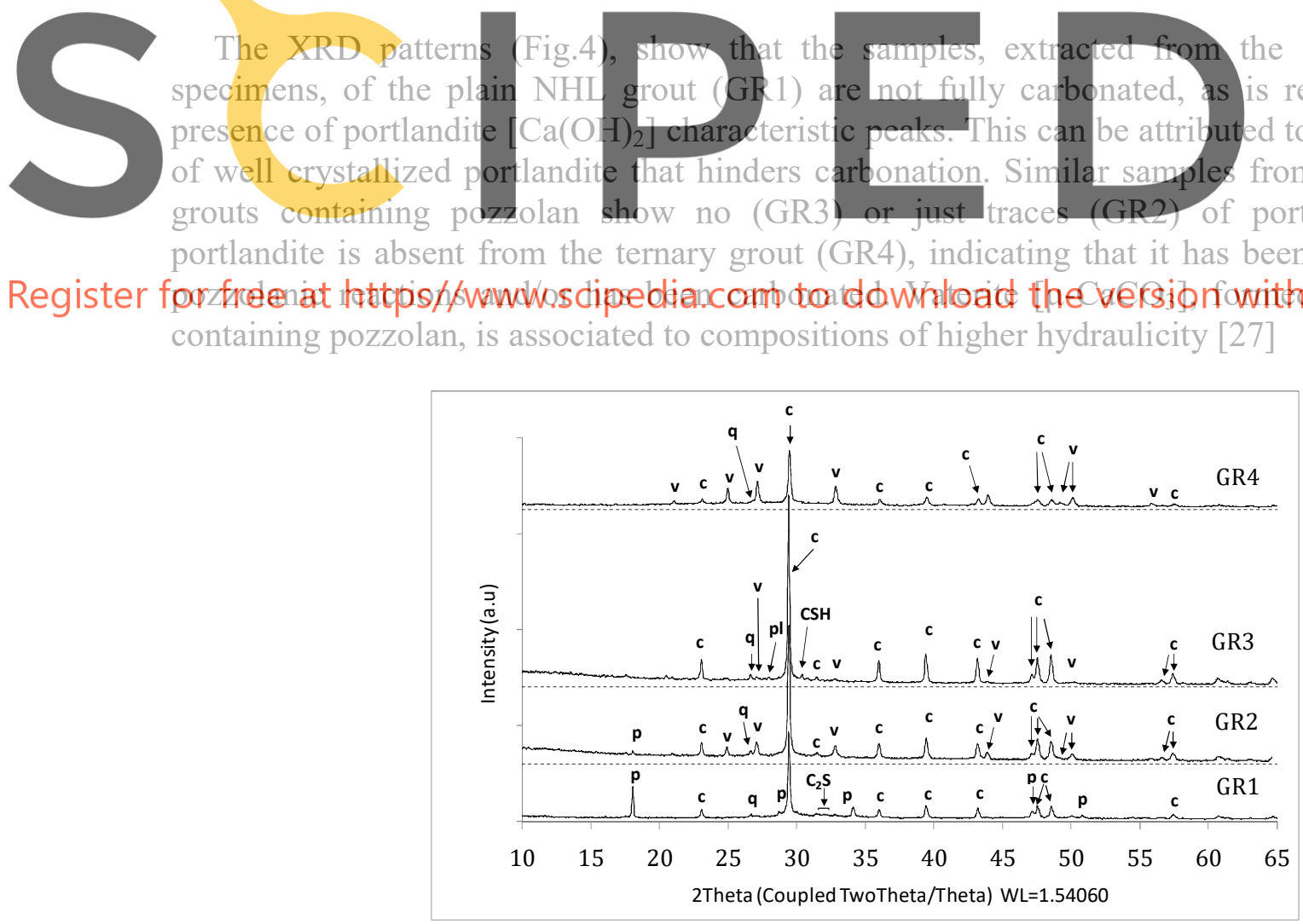

Figure 4: XRD patterns of the grouts at the age of 14 years: $\mathbf{c}$ : calcite $\left[\beta-\mathrm{CaCO}_{3}\right] ; \mathbf{v}$ : vaterite $\left[\mu-\mathrm{CaCO}_{3}\right]$; p: portlandite $\left[\mathrm{Ca}(\mathrm{OH})_{2}\right] ; \mathbf{q}$ : quartz; pl: plagioclase; $\mathbf{C S H}$ : calcium silicate hydrates; $\mathbf{C}_{2} \mathbf{S}$ : dicalcium silicate. 


\subsection{Durability against crystallization of sulphate salts of grout-only specimens}

The weight changes of all mixtures during crystallization cycles and the decay pattern are shown in Table 5. In general, all grout compositions exhibited good behaviour against the sodium sulphate attack. However, during the $9^{\text {th }}$ cycle and with drying at $50{ }^{\circ} \mathrm{C}$, the ternary grout (GR4) exhibited extensive and deep fracturing that led to the destruction of the specimens. Concerning the NHL5 based grouts, GR1 and GR2, containing 0\% and 10\% pozzolan respectively exhibited similar behaviour, while the grout GR3 (20\% pozzolan addition) appear more susceptible to the weathering effects at the same stage, even compared to GR4. However, the durability of all the grouts tested was characterized as satisfactory, as they maintained their characteristics under severe sulphate attack conditions for at least 8 cycles (drying at $50^{\circ} \mathrm{C}$ ) and for more than 11 cycles when drying was carried out at $20^{\circ} \mathrm{C}$.

Table 5: Mass changes (\%) and damage pattern during salt durability tests

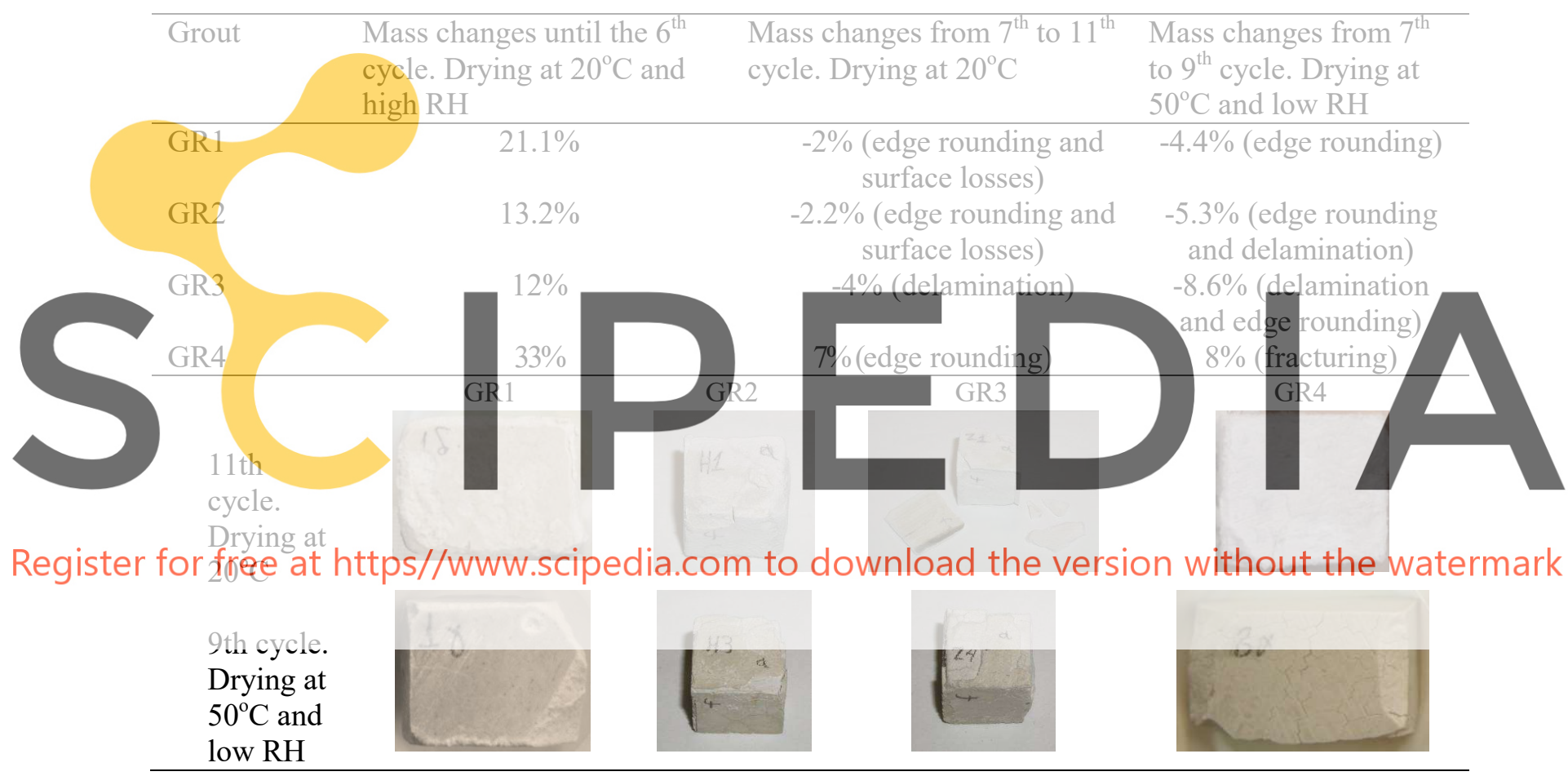

It is noted here that, unlike stone, mortar or concrete studies, the research related to the durability of grouts in an aggressive environment is very limited; thus, the behaviour of low cement ternary grouts and NHL based grouts, with or without pozzolan, against soluble salts has not yet been systematically studied. Moreover, due to the lack of a testing standard for the durability of grouts, researchers mainly use those referring to stone, modified as to the shape and size of the specimens, the type of the salt and its concentration, the apparatus, the drying temperature etc.; thus difficulties are induced for the comparison of the results. Relatively few works have been contacted on grout-only specimens [1, 10, 16, 17], while the need for developing new test methods, including the evaluation of injected specimens has been already proposed in the literature by Beçir - Şimşir [12], demonstrating that such experiments may be considered more representative of the real field conditions. 


\subsection{Penetration and solidification of the grout injected into the wall}

The SEM examination of representative samples from the injected mosaic substrata of the wall models provides data about the penetration and the solidification of the grout inside the pores, cracks and other discontinuities of a real structure, cured in real environmental conditions for many years. Small pieces were epoxy impregnated and polished cross-sections, imaged by SEM in back-scattered electron (BSE) mode. Figure 4 presents the plain NHL5 grout (GR1) having penetrated into a $1 \mathrm{~mm}$ wide crack existing in lime mortar. Near the interfaces with the porous lime mortar, the grout microstructure appears to be denser with finer particles compared to the bulk, which appears less densely packed, with coarser particles. The adhesion to the mortar appears to be good. Presumably upon entering the dry substrate, part of the grout liquid phase (i.e. water rich in $\mathrm{Ca}$ ions) is absorbed by the porous surrounding materials, attracting the thinner particles that may move in the open pores for some microns.

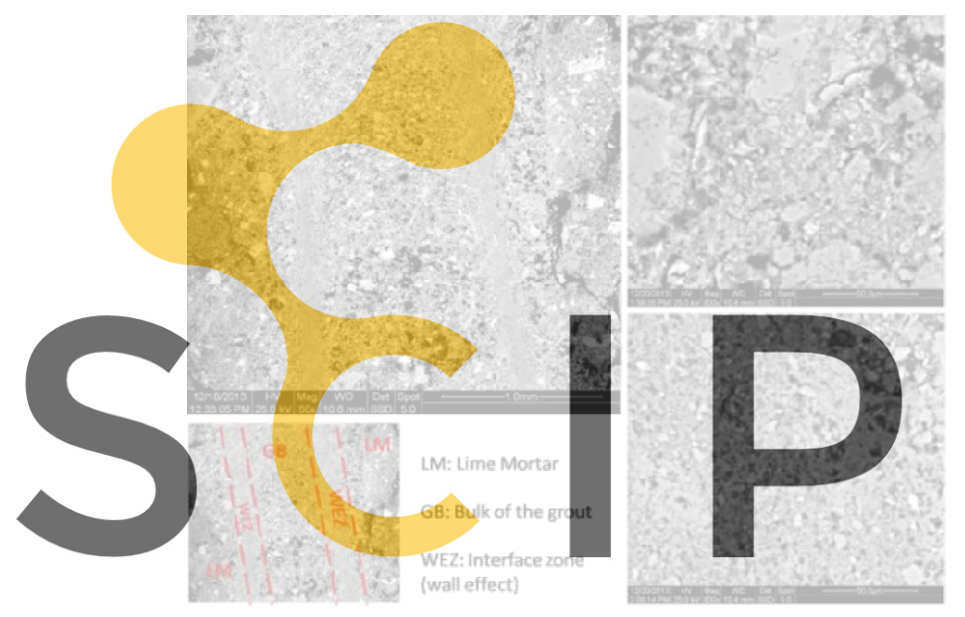

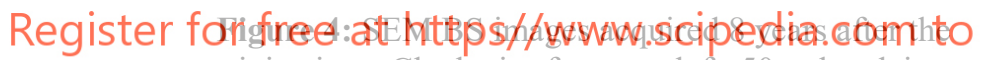
injections. Clockwise from top left: 50x, the plain NHL 5 grout (GR1) penetrating a crack; 800x, the bulk of the grout; $800 \mathrm{x}$, the interface zone between grout and lime based mortar; schematic presentation of the distinct materials and morphologies

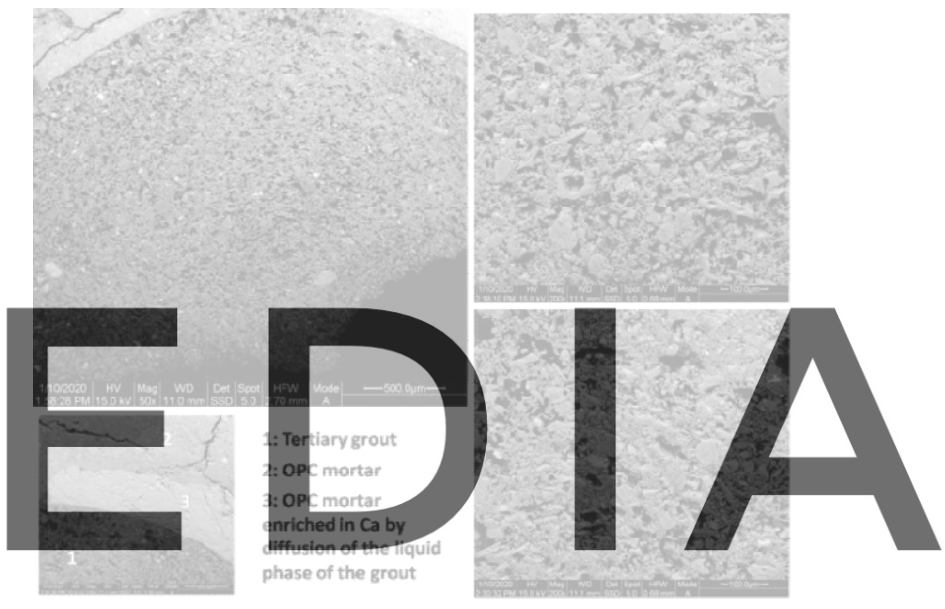

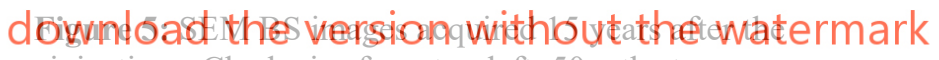
injections. Clockwise from top left: 50x, the ternary grout (GR4) filling a void; 800x the bulk of the grout; $800 \mathrm{x}$ the interface between the grout and the OPC based mortar; 100x evidence of diffusion of the $\mathrm{Ca}$ rich grout liquid phase in the OPC based mortar.

As stated in the relevant literature the water absorption out of the grout may have a beneficial effect on the adhesion between grout and substrata, provided that the grout solid phase is stable and capable to retain the water necessary for the hydration and the solidification of the grout [1]. Besides this, water absorption causes binder particles to adhere to the wall of the flow channel, but in the rest of the channel the grout that keeps on flowing, retains the same properties as the grout that is injected [15]. Representative results of reduced area EDS analyses showed that these areas are relatively richer in calcium compared to the bulk of the grout (Fig. 6), indicating that in this zone a differential diffusion of ions is likely to occur $[2,28]$. The creation of these zones may be attributed to the synergetic effect of absorption of water by the mortar and stones and probably to the wall effect [29], which does not allow larger particles to reach the wall that channels the flow of the grout, creating thus a thickening "wall effect zone". 
The observation of the ternary grout in contact with the cement based mortar, from the second wall model (Fig. 5) showed that the aforementioned phenomenon is less pronounced than in the case of the more porous lime based mortar; in this case, the interface area appeared less dense and thus more porous and poorer in calcium than the bulk (Fig. 7). As expected, the adhesion and the phases developed in this area are different, as they strongly depend on the type of grout and the nature and porosity of the substrate, as well as its water absorptivity.

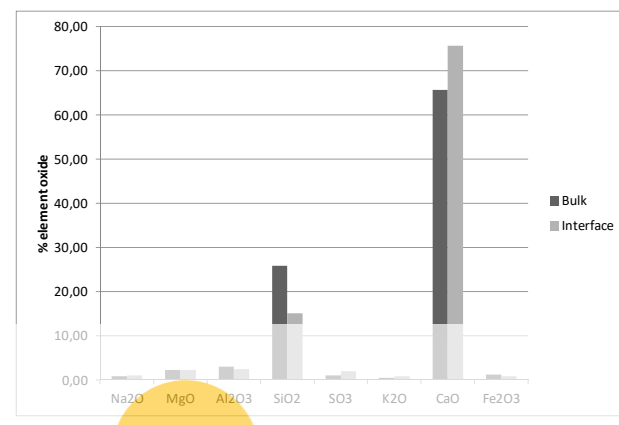

Figure 6: SEM-EDS analysis at the bulk of plain NHL5 grout (GR1) and the interface between the grout and the mosaic substrata lime mortar.

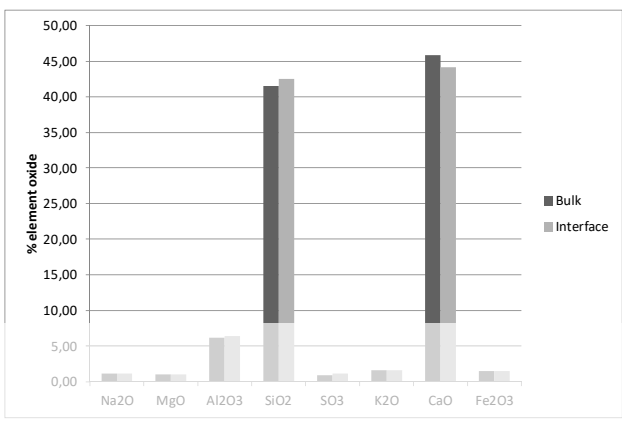

Figure 7: SEM-EDS analysis at the bulk of ternary grout (GR4) and the interface between the grout and the mosaic substrata cement mortar.

In the case of the plain NHL5 grout (GR1), XRD results of the grout samples collected from the injected walis, indicate the presence of portiandite, fully carbonated to da silicate $\left(\mathrm{C}_{2} \mathrm{~S}\right)$ in $\mathrm{GR} 1$, materials in combination to its slow hydration the grout-only specimen (Fig 4). Conclusive results based on quantitative Rietveld the minor crystal phases require higher resolution spectra and extensive disctussion of the results, which is beyond the scope of this short paper.

Register for free at https//www.scipedia.com to download the version without the watermark

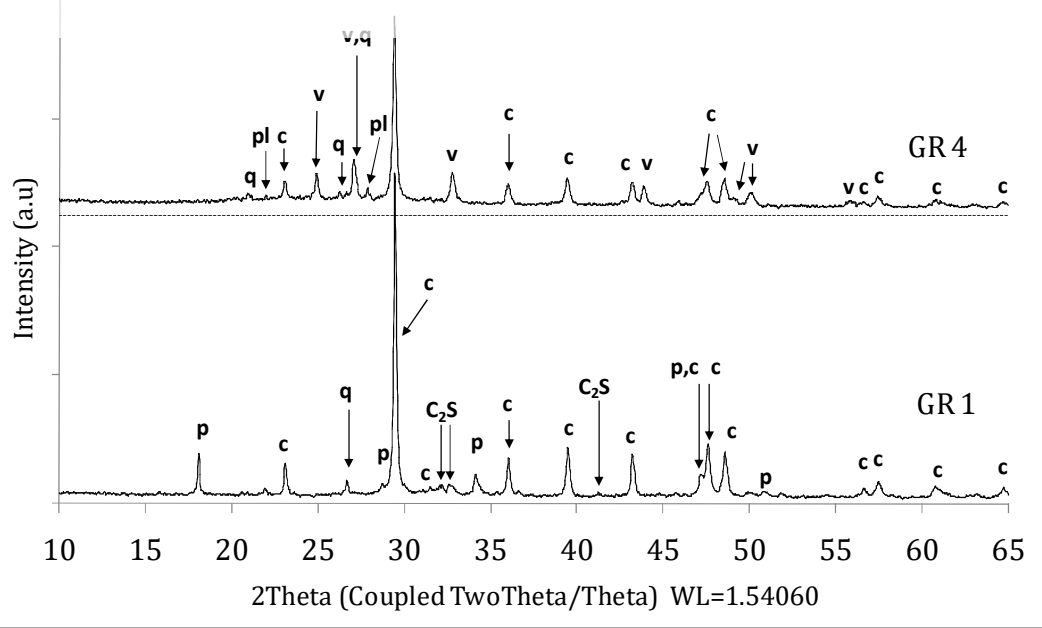

Figure 8: XRD patterns of the ternary (GR4) and the plain NHL5 (GR1) grouts. The samples were collected from the wallettes and tested 14 years after the injections: $\mathbf{c}$ : calcite $\left[\beta-\mathrm{CaCO}_{3}\right]$; v: vaterite $\left[\mu-\mathrm{CaCO}_{3}\right]$; p: portlandite $\left[\mathrm{Ca}(\mathrm{OH})_{2}\right]$; q: quartz; pl: plagioclase; $\mathbf{C}_{2} \mathbf{S}$ : dicalcium silicate 
Table 6 summarizes the results of MIP measurements on samples of the grouts injected and thus cured inside the walls. Comparison with the results of Table 3 (grout-only specimens GR1 and GR4), proves that porosity of the same grouts cured in the wall decreases, as is expected. A refinement in the pore size is also observed for the plain NHL5 grout (GR1).

Table 6: Microstructural characteristics of the grouts cured inside the wall (MIP results).

\begin{tabular}{ccccccc}
\hline & $\begin{array}{c}\text { Total } \\
\text { Porosity }\end{array}$ & $\begin{array}{c}\text { Total intruded } \\
\text { volume }\end{array}$ & $\begin{array}{c}\text { Fraction of pores } \\
(5-110 \mu \mathrm{m})\end{array}$ & $\begin{array}{c}\text { Mean pore } \\
\text { radius }\end{array}$ & $\begin{array}{c}\text { Fraction of pores } \\
(0.002-5 \mu \mathrm{m})\end{array}$ & $\begin{array}{c}\text { Mean pore } \\
\text { radius }\end{array}$ \\
\hline $\mathrm{GR} 1$ & $40.3 \%$ & $0.310 \mathrm{~cm}^{3} / \mathrm{g}$ & $0.2 \%$ & $13.4 \mu \mathrm{m}$ & $99.8 \%$ & $0.028 \mu \mathrm{m}$ \\
$\mathrm{GR} 4$ & $40.3 \%$ & $0.263 \mathrm{~cm}^{3} / \mathrm{g}$ & $1.3 \%$ & $12.3 \mu \mathrm{m}$ & $98.7 \%$ & $0.033 \mu \mathrm{m}$ \\
\hline
\end{tabular}

\section{CONCLUSIONS}

The conclusions drawn from the results of this study are as follows:

All the grout mixtures under study satisfy the injectability requirements set.

The addition of $10 \%$ pozzolan improved the physico-mechanical characteristics of the NHL grouts. The addition of $20 \%$ of pozzolan to NHL led to less satisfactory results, indicating that more intermediate dosages are necessary for the optimization of the composition. Moreover, a systematic investigation using various pozzolans and dosages is necessary in order to obtain comparative data on this topic, which is highly depended on the nature and the granulometry of the materials used.

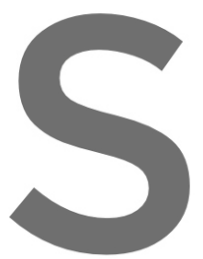

The addition

structure, the hydraulicity

pozzolan, reve consumed by p
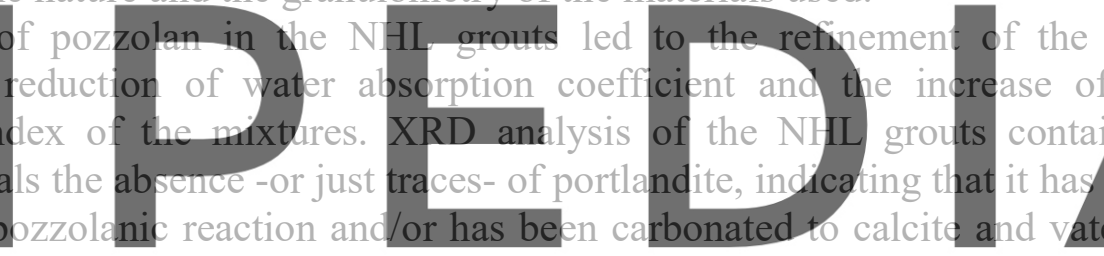

A significant amount of portlandite remains after the hardening of the plain NHL5

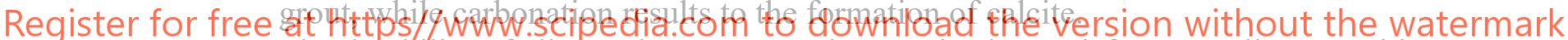
The durability of all tested grouts was characterized as satisfactory. All compositions of grout-only specimens have maintained their characteristics under severe sulphate attack conditions for at least 8 cycles. The mixtures of plain NHL5 and 90\% NHL in association with $10 \%$ pozzolan showed slightly better resistance to salt crystallization than the ternary grout. A systematic research including both grout-only and injected material specimens, may be more indicative for characterizing the durability of injected structures.

- The observation of hardened grouts injected in wallets revealed interesting phenomena, related to the flow and penetration capacity as well as the setting and the adhesion of the grout to the wall materials. At the interface with the internal discontinuities (cracks, pores, etc) of the injected substrata, a more or less dense zone is observed. Calcium enrichment or depletion, depends on both the grout and the substrate nature.

- $\quad$ The MIP results revealed a lower total porosity for the injected grouts and a slightly different pore size distribution compared to the cured grout-only specimens.

Furthermore, the data provided by this research, highlight the need for developing new testing methods for the study of injected media (composite specimens, i.e. grout and substrata) instead of grout-only specimens, which are more vulnerable to curing conditions 
and may probably lead to misleading results, mainly regarding hardened state properties.

Acknowledgements. The authors would like to express their gratitude to Dr. Ioannis Karatasios, researcher at INN/NCSR "Demokritos", and to Dr. Anastasia Michalopoulou for performing the MIP measurements. Equal gratitude is due to Katerina Kastellanou, Urania Tserpeli, Ioanna Maria Papastamati and all the staff of the Directorate of Research and Technical Support for Studies and Restoration Works of the Hellenic Ministry of Culture, for providing access and performing the mechanical testing on the matured grouts.

\section{REFERENCES}

[1] Miltiadou, A.E. Étude des coulis hydrauliques pour la réparation et le renforcement des structures et des monuments historiques en maçonnerie. Thèse de Doctorat de l'Ecole Nationale des Ponts et Chaussées. Pub. LCPC, Collection Etudes et recherches des Laboratoires des Ponts et Chaussées, série Ouvrages d'art, OA8 ISSN 1161-028X, LCPC, Décembre 1991, Paris, France, (1990), p. 278.

[2] Toumbakari, E.E. Lime-pozzolan-cement grouts and their structural effects on composite masonry walls. Ph.D. Thesis, Katholieke Univ. Leuven, (2002).

[3] Valluzzi, M.R. Comportamento meccanico di murature storiche consolidate con materiali e tecniche a base di calce. Ph.D. Thesis, Univ. of Trieste, (2000), p. 276.

[4] Miltiadou-Fezans, A., Vintzileou, E., Papadopoulou, E. and Kalagri, A. Mechanical properties of three leaf stone masonry after grouting. In: Proc. of 5th International Conference on Structural Analysis of Historical Constructions. New Delhi, India (2006).

[5] Adami, C.E. and Vintzileou, E. Interventions to historic masonries: investigation of the bond mechanism between stones or bricks and grouts. Mater. Struct. (2008) 41:255-267.

[6] Vintzileou, E. and Miltiadou-Fezans, A. Mechanical properties of three-leaf stone masonry grouted with ternary or hydraulic lime-based grouts. Eng. Struct. (2008) 30:2265-2276.

[7] Miltiadou-Fezans, A. and Tassios, T.P. Fluidity of hydraulic grouts for masonry strengthening. Mater. Struct. (2012) 45:1817-1828.

[8] Miltiadou-Fezans, A. and Tassios, T. P. Penetrability of hydraulic grouts. Mater. Struct. (2013) 46:1653-1671.

[9] Miltiadou-Fezans, A. and Tassios, T. P. Stability of hydraulic grouts for masonry strengthening. Mater. Struct.(2013) 46:1631-1652.

[10] Ferragni, D. et al. Injection grouting of mural paintings and mosaics. In: Proc. of symposium international of adhesives and consolidants, Paris, 2-8 September, (1984), pp. 110-116.

[11] Biçer-Şimşir, B. and Rainer, L. Evaluation of Lime-Based Hydraulic Injection Grouts for the Conservation of Architectural Surfaces. The Getty Conservation Institute, Los Angeles, (2013), p. 105.

[12] Biçer-Şimşir, B. Preliminary Study on the sulfate resistance of lime-based hydraulic injections grouts for the conservation of architectural surfaces. In: I. Papagianni et al. (Eds.): Proc. 4th Historic Mortars Conference, Santorini,10-12 October, (2016), pp. 548-555.

[13] Papayianni, I. and Pachta, V. Experimental study on the performance of lime-based grouts used in consolidating historic masonries. Mater. Struct. (2015) 48:2111-2121. 
[14] Miltiadou-Fezans, A. and Tassios, T.P. Holistic methodology for the mix design of hydraulic grouts in strengthening historic masonry structures. In: I. Papagianni et al. (Eds.): Proc. 4th Historic Mortars Conference, Santorini, 10-12 October, (2016), pp. 580-587.

[15] Van Rickstal, F. Grout injection of masonry, scientific approach and modeling. Ph.D. Thesis, Katholieke Univ. Leuven, (2000).

[16] Kalagri, A., Miltiadou-Fezans, A. and Vintzileou E. Design and evaluation of hydraulic lime grouts for the strengthening of stone masonry historic structures. Mater. Struct. (2010) 43: 1135-1146.

[17] Badogiannis, E., Miltiadou, A., Kalagri, A., Ipsilanti, E., Dedeloudis, C. and Vintzileou, E. Mix design and performance evaluation of grouts with super fine natural pozzolan. In: Proc. of International Conference on Structural Analysis of Historical Constructions, SAHC 2012, Wroclaw, Poland,15-17 October, (2012), pp. 773-780.

[18] Bras, A. and Henriques, F.M.A. Natural hydraulic lime-based grouts - The selection of grout injection parameters for masonry consolidation. Constr. Build. Mater.(2012) 26:135-144.

[19] Jorne, F. Injectability of hydraulic lime grouts for old masonry consolidation. PhD Thesis, Department of Civil Engineering, Univ.de Nova de Lisboa, (2016), p. 207.

[20] Luso, E. and Lourenco, P. Bond strength characterization of commercially available grouts for masonry, Constr. Build. Mater.(2017), 144:317-326.

[21] Mazzon, N. Influence of Grout Injection on the Dynamic Behaviour of Stone Masonry Buildings. PhD Thesis, Univ. degli Studi di Padova, (2010), p. 272.

[22] Silva, B., Dalla Benetta, M., da Porto, F. and Valluzzi, M.R. Compression and sonic tests to assess effectiveness of grout injection on three-leaf stone masonry walls. Int. J. Archit. Herit. (2014), 8:408-435

[23] Gökyiğit-Arpaci1, E.Y., Oktay, D., Yüzer, N., Ulukaya, S. and Ekşi-Akbulut, D. Performance Evaluation of Lime-Based Grout Used for Consolidation of Brick Masonry Walls. J. Mater. Civ. Eng. (2019), 31:04019059.

[24] Schindelin, J. et al. Fiji: an open-source platform for biological-image analysis. Nat. Methods, (2012), 9:676-682.

[25] Espinosa-Marzal, R.M. and Scherer, G.W. Advances in understanding damage by salt crystallization. Accounts Chem. Res. (2010), 43:897-905.

[26] Steiger, M. and Asmussen, S. Crystallization of sodium sulfate phases in porous materials: the phase diagram $\mathrm{Na}_{2} \mathrm{SO}_{4}-\mathrm{H}_{2} \mathrm{O}$ and the generation of stress. Geochim. Cosmochim. Act. (2008), 72:4291- 306.

[27] Elsen, J., Van Balen, K. and Mertens G. Hydraulicity in historic lime mortars: a review, In: J. Valek et al. (Eds): Historic Mortars, Rilem Bookseries, (2012), pp.125-139.

[28] Breton, D., Carles-Gibergues, A., Ballivy, G. and Grandet, J. Contribution to the formation mechanism of the transition zone between rock-cement paste. Cement Concrete Res. (1993), 23:335-346.

[29] Roussel, N. and Gram, A., Physical Phenomena Involved in Flows of Fresh Cementitious Materials. In: N. Roussel, A. Gram (Eds): Simulation of fresh concrete flow, STAR RILEM Technical Committee 222-SCF, Springer, (2014), pp. 20-22. 